\title{
Renewable microgrid projects for autonomous small-scale electrification in Andean countries
}

\author{
A. López-González ${ }^{1}$, B. Domenech ${ }^{2,3} *$, D. Gómez-Hernández ${ }^{1}$, L. Ferrer-Martî2,4 \\ ${ }^{1}$ Institute of Sustainability, Universitat Politècnica de Catalunya (Spain) \\ ${ }^{2}$ Institute of Industrial and Control Engineering, Universitat Politècnica de Catalunya (Spain) \\ ${ }^{3}$ Electricity Research Centre, University College Dublin (Ireland) \\ ${ }^{4}$ Department of Mechanical Engineering, Universitat Politècnica de Catalunya (Spain) \\ Contact $(*)$ Av. Diagonal 647, Pavilion H, Floor 11, 08028, Barcelona (Spain) \\ bruno.domenech@upc.edu; (+34) 934.016.579
}

\begin{abstract}
Nowadays, $84 \%$ of the world population without access to electricity is located in rural areas of developing countries. In particular, in the Andean countries, about 10.4 million people lack of access to electricity, mainly in isolated poor regions. Considering the relevance of electricity in overcoming poverty and promoting socioeconomic development, local-regional-national governments, supported by international organizations, are making efforts to achieve full rural electrification. In this regard, renewable microgrid projects are an effective alternative where the national grid extension has limitations. The literature on the design of such projects is significant. However, when evaluating experiences, most works focus on an analysis of projects' performance from a technical and/or economical point of view. In contrast, very few literature has been reported on the comparison of such experiences from the perspective of the design process itself and how decisions are taken by project developers. In this article, five rural electrification experiences in Andean Countries (Bolivia, Ecuador, Peru and Venezuela) are reviewed, analyzing the decisions taken across the design process and showing the suitability of these technologies to extend access to electricity. In the target projects, first, a preliminary analysis is carried out to estimate the energy resources and demand. Next, the system is designed and implemented to meet the demand using the available resources. The five projects illustrate different options for the electrical generation (single, hybrid or combination of technologies), storage (battery or diesel backup) and distribution (microgrid or individual systems), as well as different methods for data gathering and systems design. In addition, a comparison of projects' real behavior is carried out and their technical performance in terms of energy production and suitability of the technologies implemented is analyzed. These projects can be a good reference for the dissemination of such technologies in future projects in the Andean countries and abroad.
\end{abstract}

Keywords: rural electrification; renewable energy; microgrids; Andean countries; HOMER

\section{Introduction}

Nowadays, about 1.2 billion people lack of access to electricity [1]. Over $95 \%$ of such population lives in developing countries and $84 \%$ in rural areas. Most rural communities without electricity are located in scattered territories with very low population density and where the national grid extension cost is very high. Consequently, an estimated $70 \%$ of communities must be electrified using isolated autonomous systems [2]. When considering sustainability-related aspects [3], diesel generators have many limitations, such as greenhouse gas emissions and external dependences on fossil fuels that can significantly increase the project costs. In contrast, autonomous electrification systems based on renewable energy take advantage of local resources and are increasingly being deployed [4], especially in developing countries [5][6]. 
Among the renewable energy technologies commonly used for autonomous systems, microhydro power plants take advantage of river waterfalls and flows to generate electricity, and represent a cheap and reliable option, though limited by the availability of nearby rivers [7]. Solar photovoltaic (PV) energy has been mainly used thanks to its availability almost everywhere in the world [8][9]. Meanwhile, small-scale wind energy receives increasing attention [10][11]. Finally, hydro-kinetic turbines, that produce electricity directly from river flows, have a low cost and can be installed in communities near rivers [12].

With regards to the distribution configuration, individual systems have generally been implemented (independent generation and storage for each consumption point), but they have limitations in the ability to include new users and adapt to demand increases. In contrast, microgrids (that concentrate generation and storage for several consumption points) have a greater flexibility in consumption, can reduce costs due to economies of scale, can take advantage of high resource areas and can improve cooperation between users, strengthening socioeconomic development [13]. All these advantages favor the use of microgrids in rural areas of developing countries [14].

Figure 1 shows the common scheme for autonomous systems, which includes different optional generation technologies (wind, solar, micro-hydro and hydro-kinetic turbines) and distribution configurations (microgrids and individual systems). For wind turbines, PV panels and hydro-kinetic turbines, controllers protect batteries from overloads and deep discharges. Batteries store the energy to cover the mismatch between generation and consumption. After storage, inverters transform the DC current into $\mathrm{AC}$, which is more suitable for residential appliances. Electricity is distributed to end-users either through microgrids (low or medium voltage, in which case transformers become necessary) or individual systems. Microgrids have a radial scheme, given its lower cost in front of other options. Finally, a meter can be installed at each point to control its consumption.

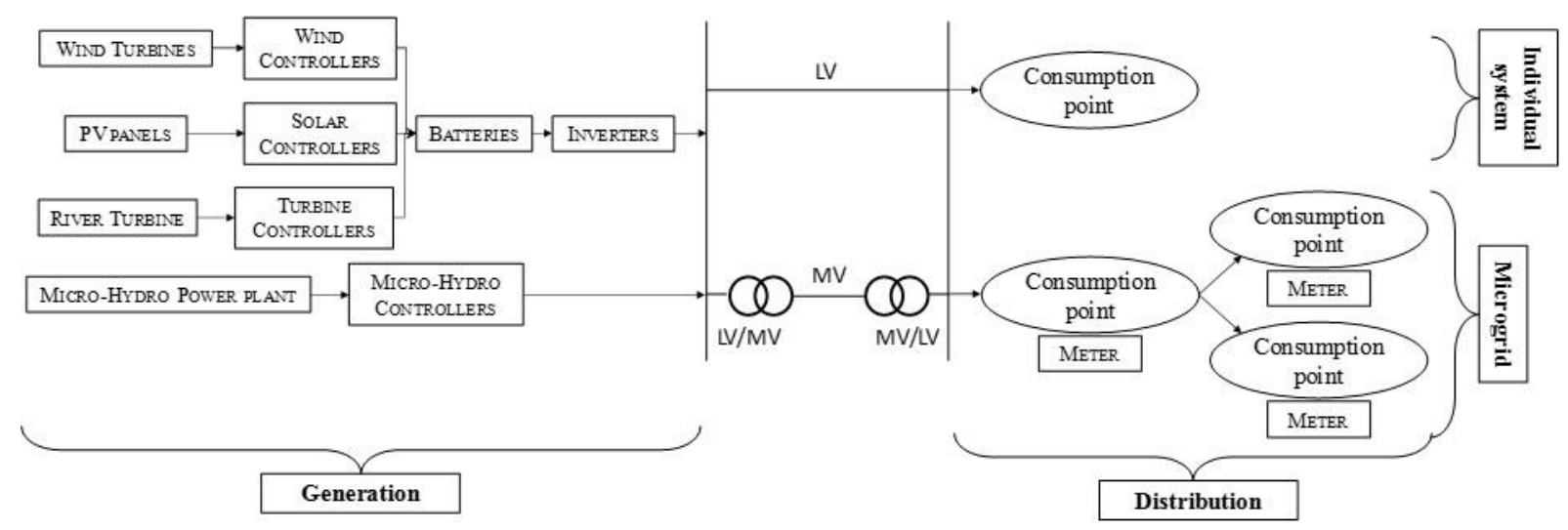

Figure 1. Typical scheme for autonomous rural electrification systems with renewable energy

Relevant autonomous projects have been deployed in the three regions with the higher rural electrification requirements: Asia, Africa and Latin America. In Asia, for instance, in the island of Xiao Qing Dao (China), a microgrid was implemented, consisting of four $10 \mathrm{~kW}$ wind turbines, a $30 \mathrm{~kW}$ diesel generator, a $40 \mathrm{~kW}$ inverter and a battery bank; and its 
socioeconomic impact was well appreciated by end-users [15]. In fact, in China, the "Township Electrification Program" was launched in 2002, which was the largest renewable energy-based program in the world [16]. Under this framework, 51 wind-PV and $670 \mathrm{PV}$ microgrids were installed in 20 months, providing electricity to more than 340,000 people. In the community of Buayan (Malaysia), a $14 \mathrm{~kW}$ micro-hydro power plant operates between 12 and 24 hours, depending on whether the dry or rainy season, supplying 22 houses; while the remaining 18 houses are supplied by individual PV systems. Also in Malaysia, the community of Terian gets electricity from a $5 \mathrm{~kW}$ micro-hydropower plant [17]. In India, around 75,000 villages lack of access to electricity; and among the planned $2 \mathrm{GW}$ power capacity expansion until 2022, an estimated $1.1 \mathrm{GW}$ will be covered by microgrids. In the northern district of Leh, a $100 \mathrm{~kW}$ and a $40 \mathrm{~kW}$ PV microgrids with battery and diesel generator backup were deployed in the villages of Tangtse and Nyoma, respectively [18]. In the community Koyalapada, also in India, a $120 \mathrm{~kW}$ PV microgrid was deployed to provide lighting for 232 houses and feed a water pump located in a nearby aquifer [17]. The Indian government esteems that new microgrids will have an average capacity of $250 \mathrm{~kW}$, mainly based on PV energy. Around one hectare per benefited community is needed for PV panels, in addition to the storage and diesel generators backup [19].

Since mid-2015, Africa is involved in an evaluation and planning process under the "Sustainable Energy for All" program of the United Nations. The program promotes microgrids as a technology to achieve the goal of universal access to energy [20]. By the end of 2015, 44 African countries had joined this initiative, and the Sustainable Energy Fund for Africa is already working on the development of microgrids in many of them. The Tanzanian government estimates that, through such programs, 250,000 people will be annually incorporated to the electricity service. As a first phase, hybrid PV/diesel/battery microgrids have been projected for 16 villages, 32 schools, 12 health centers and 77 religious buildings, thus benefiting 82,000 people [21]. Similarly, in the rural community of Ditunga (Democratic Republic of the Congo), a radio station, a school and a poultry farm were electrified through a wind/PV/battery microgrid. The project benefited 20,000 people, including 2,000 school students [22]. In the community of Gada (Nigeria), a $5 \mathrm{~kW}$ microgrid based on hydro-kinetic energy was installed, providing around $15 \mathrm{kWh}$ /day to 7 houses. The river has a seasonal flow, and a special channel was adapted to ensure generation even during the dry season [22].

In Latin America, the Brazilian government launched the program "Light for all" [23], through which the 89 houses of the Lenço island were electrified using a $40 \mathrm{~kW}$ wind-PVdiesel-battery microgrid [24]. In the largest Caribbean islands (Cuba, Dominican Republic and Haiti) renewable energy reached $22.8 \%$ of the energy matrix in 2006 [25]; mainly thanks to biomass. More specifically, the Cuban government is promoting the sustainable energy development of the Isla de la Juventud. In this island, the community of Cocodrilo, with 80 houses and 230 inhabitants, was electrified through a $50 \mathrm{~kW}$ microgrid whose primary energy source is biomass gasification [26].

Among the Latin American countries, this study is focused on Bolivia, Ecuador, Peru and Venezuela, which are part of the Andean region. These countries share most of their history, 
geography and demography, showing remarkable similarities in political, economic and social aspects. In this region, people live with a high economic dependence on natural resources, such as oil and mining. Foreign investment is mainly concentrated in such sectors, while rural-related activities are mostly abandoned [27]. For that reason, the population is concentrated in major cities and their suburbs, while $78 \%$ of the territory has a density lower than 50 inhabitants $/ \mathrm{km}^{2}$. All the countries in the region have made significant efforts to extend access to electricity within their territories, increasing between 1990 and 2012 from $67.0 \%$ to $90.5 \%$ in Bolivia, from $89.0 \%$ to $97.2 \%$ in Ecuador, from $69.0 \%$ to $91.2 \%$ in Peru and from $98.0 \%$ to almost $100.0 \%$ in Venezuela [28]. However, according to Fontaine [27], the abundance in fossil fuels, and consequently their low cost of opportunity, has a significant influence in delaying the transition of the energy matrix into renewable energy-based technologies. Therefore, rural electrification based in renewable energy represents a particular challenge in these countries. In fact, there are still 10.4 million people without electricity, especially in rural and remote areas [29]. This analysis of experiences focuses on such isolated zones, which concentrate the higher need for investment in electrification.

In this paper, five isolated renewable microgrid electrification projects in the Andean region are described and compared, illustrating some of the most used generation, storage and distribution technologies worldwide. These projects have been deployed by NonGovernmental Organizations (NGOs) and/or local-national governments. Across the description, special emphasis is put on how decisions are taken by the developer institutions during the projects design. In each case, a technical description of the project is provided, focusing on the energy resources and demand assessments as well as on the design of the electrical generation, storage and distribution systems (Section 2). Then, the projects are compared and their real technical behavior is analyzed to be used as examples for future systems (Section 3). Finally, the main conclusions are presented (Section 4).

\section{Projects description}

In this section, five rural electrification projects are presented. First, two projects based on a unique generation technology are described: a PV microgrid in Saqa'saqa, Bolivia (Section 2.1); and a micro-hydro power plant in El Regalado, Peru (Section 2.2). Then, hybrid projects that combine two generation technologies are explained: a wind-PV microgrid and individual PV systems in Jacuque, Venezuela (Section 2.3); and a microgrid supplied by hydro-kinetic turbines and PV panels in San José del Coca, Ecuador (Section 2.4). Finally, a project that combines different technologies in Alto Peru, Peru (Section 2.5) is shown. For each case, first the community context, including demand and resource analysis, is presented and then the electrification design process itself is described.

\subsection{Saqa'saqa (Bolivia)}

Considering data from International Energy Agency [30] and World Bank [29], it has been estimated that there are 1.56 million people without access to electricity in Bolivia, $90.45 \%$ 
of them living in rural communities. This country has the lowest Rural Electrification Rate (RER) in the Andean region, as $56.8 \%$ of people living in these areas lack access of electricity. In particular, the project in Bolivia is located in the region of Potosí, where the Human Development Index (HDI) was 0.554 while the RER was $38 \%$, at the moment of implementing the project. In this sense, the Andean Rural Electrification Program (PAER, for its acronym in Spanish, 2005-2012), led by Engineering Without Borders (EWB, Spain) promoted access to electricity by means of renewable energy in the Andean area of Bolivia, Ecuador and Peru [31]. Some of the local and international partners that participated in the program were: Practical Action (PA, Peru), CINER (Bolivia), Mosoj Causay (MC, Bolivia), FEDETA (Ecuador), GADMFO (Ecuador), Green Empowerment (GE, US) and the Universitat Politècnica de Catalunya (UPC, Spain). More specifically, the PAER in Bolivia focused on the Cochabamba region, where access to electricity is a handicap due to the high scattering between houses and communities as well as the limited payment capacity of inhabitants.

The project described below was implemented in the Quechua community of Saqa'saqa, in the province of Potosi. The community consists of 8 families and a population of 25 people, located at an altitude of more than 3900 m.a.s.l. The population depends on the nearby community of Layupampa, one hour away, where population attends to go to school, receive medical care or work as laborers or beggars. The electrification project was installed in 2008 and was the first isolated PV microgrid system in Bolivia. The over sizing of equipment has allowed some flexibility when adding or disconnecting certain users, given the migration during these years.

\subsubsection{Preliminary evaluation of the project}

Prior to the electrification project described here, Saqa'saqa had no electricity at all, so population used different alternatives (such as kerosene lamps, flashlights or candles) for lighting purposes. Considering the location of the community, the following energy sources whose potential could be enough to supply population requirements were analyzed:

- National grid extension: it was discarded since the community is located in a remote region, not covered by the government plans for grid expansion.

- Non-renewable resources: they were discarded given the remoteness of the community and the lack of means for fuel transportation.

- Water resource: it was discarded because the nearest river had a very variable flow, depending to the seasons, and it even dries at some periods of the year.

- Wind resource: it was discarded as the locations with a sufficient wind potential were nearby mountain peaks too far from the village.

- Solar resource: this option was chosen because the radiation in the least potential month (June) is $4.15 \mathrm{kWh} / \mathrm{m}^{2}$, which is an acceptable value for electrical generation. 
- Surveys were conducted with the families of the community, through which a demand of $400 \mathrm{Wh} /$ day was estimated. This value considers three points of illumination and a radio plus a consumption of $50 \mathrm{~W}$ for a maximum of 4 hours.

\subsubsection{Design and implementation of the project}

Once the generation technology was decided, three different options for electrical distribution were studied:

- AC microgrid. The generation and storage equipment (PV panels, controllers, batteries and inverters) would be installed at a single location. Consumption meters would be included to control the demand of each user. This option would represent an AC service at a lower maintenance cost than independent supplies for each house, although at a higher initial investment.

- Individual AC systems. An independent supply would be installed for each house, consisting of a PV panel, a battery, a controller and an inverter. With this option, the consumption of each family would be independent, easing the implementation of this technology. However, the poor quality of low-powered inverters could be a limitation.

- Individual DC systems. This option would save costs of inverters as well as avoid technical issues in such devices. In addition, this configuration has already been used in previous projects in the region, proving its suitability. However, the loads to be connected would be significantly limited.

To take the final decision, the institutions behind this project (EWB, CINER and MC) considered the following aspects. First, although the maintenance of DC systems would be less expensive, this option was rejected because end-users showed interest in utilizing AC loads. In addition, DC replacements are more expensive, what could be a limitation. Regarding reliability, a concern about low-powered inverters arose in technical experts, in the case of implementing individual AC systems. Consequently, it was finally decided to implement a PV microgrid.

\subsection{El Regalado (Peru)}

In Peru, 6.2 million people have no access to electricity, 93.95\% of them in rural communities in the Andean and the Amazon regions. Around 1 million were located in the region of Cajamarca (in the northern Andean highlands), which had the lowest electrification rate across the country [32]. In Cajamarca (Peru), the HDI was 0.563 and the RER was $17.7 \%$. In this context, PA had been implementing projects mainly using micro-hydro power plants for the last three decades. One of the projects was El Regalado, located in the province of San Pablo [33]. The project benefited a total of 175 people directly, in addition to many inhabitants from nearby communities. This project involved electrification for domestic purposes, as well as for the development of productive activities that have led to a significant improvement in quality of life of end-users. The project was installed in late 2009, and given 
the continuous resource in which it is based (a river flow), it has represented the economic development of population, thanks to the access to many services and social benefits similar to urban levels.

\subsubsection{Preliminary evaluation of the project}

One of the strategies commonly used by PA is to prioritize electrification projects where villagers request for such service by themselves, thus easing the project success. After this first step happened in El Regalado, a community assessment was carried out in order to identify the relevant characteristics of population with regard to the design of the electrification system. This evaluation was conducted by a group of technical and social experts.

First, the socioeconomic characteristics of inhabitants were gathered. This process was done together with the entire population, in order to collect the expectations and needs of all the project end-users. After analyzing this information, 31 houses and 4 institutions (a preschool, a school, a health center and a community center) were identified to be electrified. In addition, the day and night demands were estimated, in order to examine the peak load period. In addition to domestic and institutional demands, public lighting and industrial consumption, as a result of the development of productive activities with the introduction of electricity, were also considered. In short, considering the simultaneity and utilization factors, a daytime demand of $5.0 \mathrm{~kW}$ and a nighttime demand of $5.7 \mathrm{~kW}$ were estimated. Considering the power requirements and an estimation of usage hours of each appliance, a total of $25.7 \mathrm{kWh} /$ day energy demand was estimated for houses, public centers and productive activities. Consequently, the project was designed for the nighttime peak load, more specifically, a generating capacity of $10.1 \mathrm{~kW}$ was determined, considering a $10 \%$ of losses in the electrical distribution networks as well as a demand increase of $60 \%$ for the next 15 years.

To cover this generation capacity, the energy resources in the region were studied. In particular, a $40 \mathrm{~m}$ waterfall located $1 \mathrm{~km}$ far from the center of the community, with a flow rate between 80 and $100 \mathrm{l} / \mathrm{s}$ in dry months was identified; although a 60 1/s flow was considered for reliability purposes. With this information, a $12 \mathrm{~kW}$ hydro power potential was determined. Assuming that the generation potential thoroughly exceeded the expected peak load, no other energy resources (such as wind or sun) were taken into account for the project.

\subsubsection{Design and implementation of the project}

Once defined the electrical demand of end-users and the capacity of the micro-hydro power plant, each component was designed as described below:

- Water intake. This system collects water from the river. It was designed taking into account a continuous water flow of $60 \mathrm{l} / \mathrm{s}$ and it was placed at a strategic part of the river to minimize the overall environmental impact. 
- Driving canal (Figure 2). This system drives the water from the intake till the sand trap. A $920 \mathrm{~m}$ distance was covered, considering a flow of $60 \mathrm{l} / \mathrm{s}$ and a 2-3\% gradient for proper water circulation. A PVC pipe was used coated with concrete, installing inspection boxes every $50 \mathrm{~m}$ to ease maintenance activities.

- Sand trap and forebay. This system is located prior to the waterfall itself. It was designed considering a flow of $60 \mathrm{l} / \mathrm{s}$ and including a cleaning system to remove small particles from the water though a decantation process.

- Pressure line. This system conducts water across the waterfall. It was designed according to the flow of $60 \mathrm{l} / \mathrm{s}$ and $40 \mathrm{~m}$ height fall. PVC pipes were used, joining them through flexible rubber rings.

- Power box. It was designed to protect the power turbine and a controller, and includes a space to shelter the operator during operation and maintenance activities and some tools.

- Electromechanical equipment. A $12 \mathrm{~kW}$ Michell Banki turbine was installed, given its lower cost and easier technical maintenance in front of other options. In addition, an asynchronous induction generator and an electronic charge controller were implemented.

- Electrical network. To distribute the electricity from generation to end-users, a radial microgrid was used. Medium voltage (LV) wires were utilized for the $1000 \mathrm{~m}$ between the generation point and the center of the community, while low voltage (LV) to distribute the electricity to each house and institution.

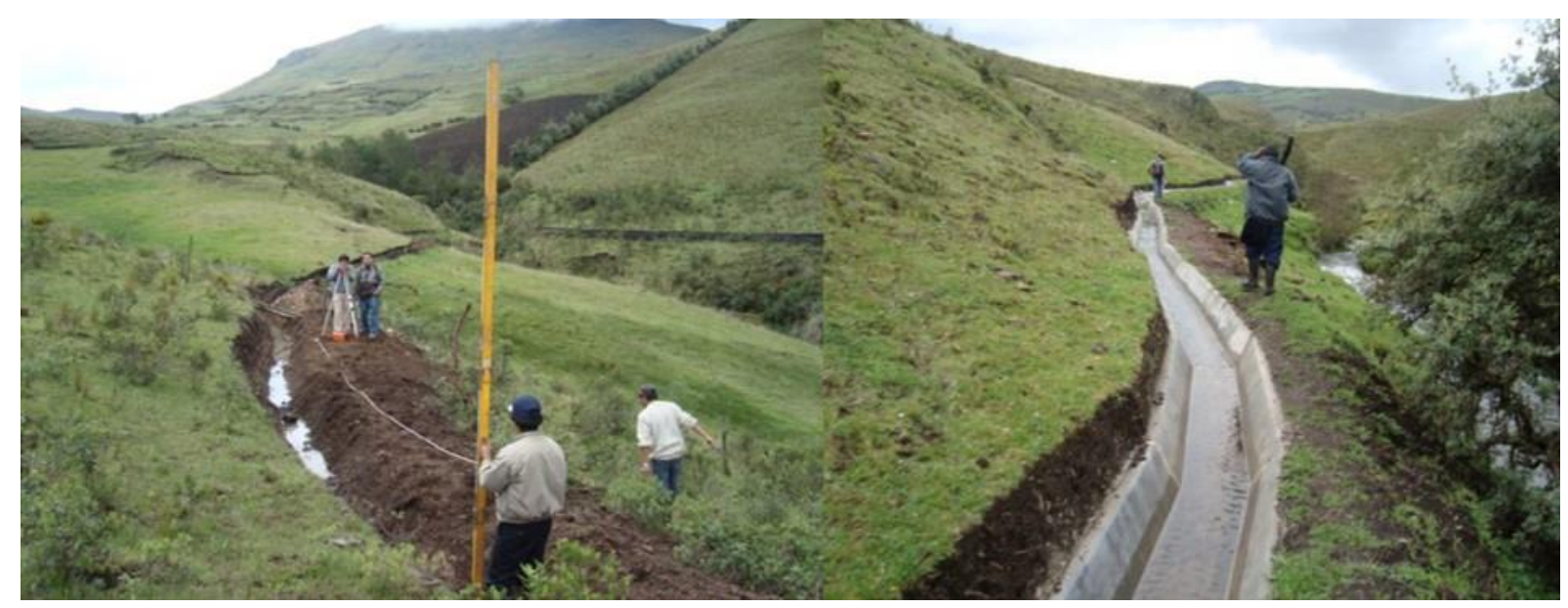

Figure 2. Construction of the micro-hydro power plant of El Regalado, Peru [31]

\subsection{Jacuque (Venezuela)}

According to the Latin American Energy Organization, Venezuela is the country with the highest degree of electrification in the region [35], offering coverage to more than $99.5 \%$ of its total population, not serving only about $7.5 \%$ of the rural population (155 thousand people) located in rural, indigenous and border communities of this country. In part, this is because of the national government, through the Foundation for the Development of Electric Service (Fundelec), efforts to install individual PV systems and wind-PV microgrids, using battery and diesel generator backup, for small communities between 10 and 40 houses. In 2013, more than 3,000 individual systems and 14 microgrids had been installed. Within this context, Falcon (HDI 0.830, RER 92.5\%) is one of the states with the greatest potential in 
renewable energy, and particularly the Paraguaná peninsula. Jacuque is a small community located in such peninsula, with around 110 inhabitants distributed in 24 houses and a school, spread across $10.2 \mathrm{~km}^{2}$. The emplacement of the community ensures the wind potential, from trade winds, and a significant solar potential, due to the tropical latitude in northern Venezuela. The Jacuque project was implemented in 2009, under the program "Sowing Light" promoted by Fundelec, being the first rural electrification project launched in 2005 . The Jacuque system has been a model for the development of 13 additional projects in western Venezuela. The process used here is the same as in the remaining projects.

\subsubsection{Preliminary evaluation of the project}

The design process started with a request to Fundelec by the Jacuque community council, which is a neighborhood organization aiming to manage solutions for population problems, such as water, electricity, health and education. Then, Fundelec technicians addressed the request based on some priority criteria established by the Venezuelan government. These criteria pretend to identify communities that can be included in the program as well as to determine the electrification system to be implemented. In particular, technicians collected the data needed for the evaluation of criteria and the subsequent system design (such as the location of the consumption points, community accesses, etc.). Regarding the energy resources, Fundelec has measurements of wind speed and solar radiation at several points in Paraguaná, which were used as reference for sizing equipment. The prioritization criteria are:

- The community must have less than 500 inhabitants and be located at least $10 \mathrm{~km}$ far from the national grid. In addition, no electrification project nor grid extension plans must exist at the region.

- The community must be a permanent settlement, not a transient one, such as seasonal fishing, planting and harvesting refuges. Priority is given to isolated, indigenous or frontier communities and those located close to environmentally protected areas.

- The community must be properly managed through a community council; i.e.they must have a local organization able to manage the electrification system and organize population for an efficient use of energy and an adequate maintenance of equipment.

- There must be a local productive activity and the coverage of other social programs from the government addressing issues such as education, food or tourism.

Once Jacuque was selected, a microgrid was conceived to supply to the concentration of houses near to the center of the community, while for far neighbors where the microgrid extension would be too expensive, individual systems were considered. The houses included in the microgrid were selected within a maximum radius of 200 meters from the generation system. According to the distribution of each house across the territory, the microgrid location that allows encompassing as many users as possible was chosen, thus extending the benefits of this configuration to the largest number of inhabitants. Fundelec, estimated an average consumption of 4,900 Wh/day per school, 3,700 Wh/day per health center and 
2,000 Wh/day per house, which includes telecommunications and lighting, as well as a refrigerator and low-powered appliances.

\subsubsection{Design and implementation of the project}

As shown in Table 1, the rural electrification program promoted by Fundelec has been standardized and considers the possibility of implementing four different configurations, depending on the number of houses to be supplied [36]. Each configuration includes the use of wind turbines and PV panels as main technologies, a battery support to cover the mismatch between generation and consumption periods, and a diesel generator backup to ensure supply in the case of large lacks of wind and sun.

Table 1. Typical configurations for hybrid microgrids under the Fundelec program [36]

\begin{tabular}{cccc}
\hline \multirow{2}{*}{ No. of houses } & Wind turbines $[\mathbf{k W}]$ & $\begin{array}{c}\text { Generation capacity } \\
\text { PV panels [kWp] }\end{array}$ & Diesel generator [kVA] \\
\hline$\leq 10$ & $1 \times 3$ & 3 & 10 \\
$\leq 20$ & $1 \times 6$ & 6 & 15 \\
$\leq 30$ & $1 \times 3 ; 1 \times 6$ & 9 & 20 \\
$\leq 40$ & $2 \times 6$ & 12 & 25 \\
\hline
\end{tabular}

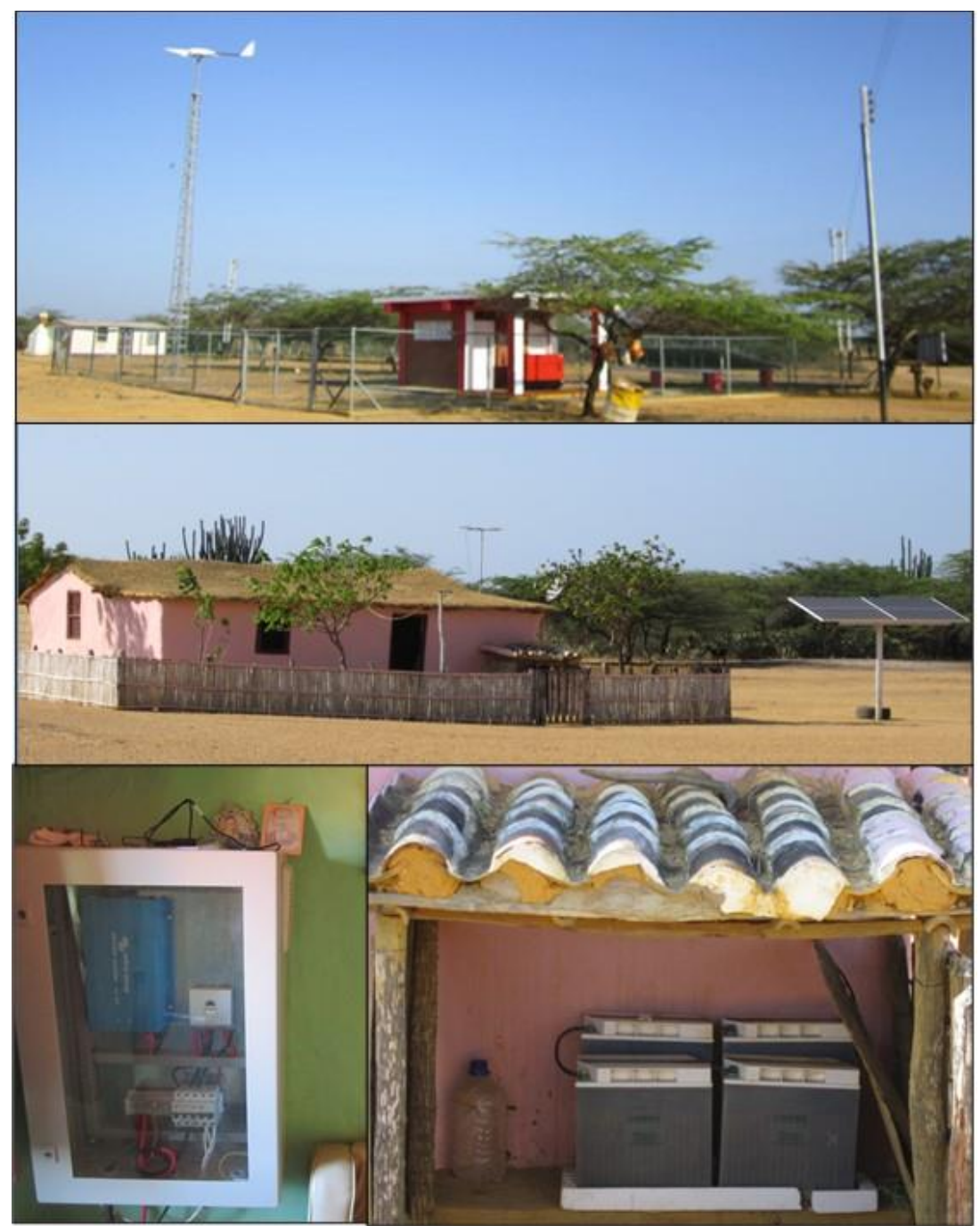

Figure 3. Microgrid (top), individual system (center) and inverter/battery (bottom) in Jacuque, Venezuela 
In Jacuque, as the microgrid was conceived for 10 houses and the school, the first configuration was chosen. Hence, the microgrid was installed, taking advantage of a solar radiation at the area higher than $6.7 \mathrm{kWh} / \mathrm{m} 2 /$ day and a wind speed at $10 \mathrm{~m}$ height exceeding $7 \mathrm{~m} / \mathrm{s}$. Figure 3 (top) shows the $3 \mathrm{~kW}$ wind turbine, the $3 \mathrm{kWp}$ PV panels (20 modules of $150 \mathrm{Wp}$ ) and the $10 \mathrm{kVA}$ diesel generator. The central-red building shelters the generator, the 24 batteries (1080 Ah each) and the two inverters ( $3 \mathrm{~kW}$ each) as well as battery charge controllers. These devices monitor events in the system to ensure that failures can be later reviewed by Fundelec technicians. The electricity is then distributed through a $120 \mathrm{~V}$ singlephase network. Finally, it should be noted that the diesel generator has an estimated autonomy of 10 hours, working at peak load. The cost of fuel in Venezuela is highly subsidized, making it easily affordable for the population.

As mentioned before, together with the microgrid, 14 individual PV systems for scattered houses were conceived. Each of such systems consists of four $150 \mathrm{Wp} \mathrm{PV} \mathrm{panels,} \mathrm{four}$ batteries (300 Ah each), located sheltered from rain and sun, along with an inverter (750 VA). Figure 3 (center and bottom) shows such a system. Note that a water container near to batteries is used for their maintenance by the house inhabitants.

\subsection{San José del Coca (Ecuador)}

In Ecuador, the RER rate is about $77.2 \%, 1.22$ million people in rural communities have no access to electricity and most of them are located in the Amazon. In particular, in the province of Orellana the RER is only $48.3 \%$. In this context, GADMFO, FEDETA and EWB promoted the installation of a hybrid microgrid supplied by a hydro-kinetic turbine and PV panels for the Kichwa community of San José del Coca. These projects, under the PAER program, benefited 54 families, the health center, the school, the high school and the community center. The technologies used here, helped to develop technical and management capacities in end-users. The project, installed in 2010, has been beneficial not only for improving socioeconomic conditions of population, but also as a pioneer project in terms of technology transfer, self-management and technical training in the Amazon region.

\subsubsection{Preliminary evaluation of the project}

First of all, a characterization of the social, cultural and economic aspects of the region was carried out, as well as the assessment of the energy demand and resources. In detail, two inspections were conducted for community identification; as a result, San José del Coca was chosen for the development of a microgrid using the hydro-kinetic potential of the Coca river. Thus, interviews were conducted with 33 beneficiaries, who attended to the workshops organized by the project promoters. This process combined sociologists, to identify end-users needs, and technicians, to design the electrification system satisfying such needs. In addition to formal surveys, informal dialogues with population and professionals working in the area were very relevant to go in deep into a community insight. On its behalf, the evaluation of the energy demand was developed in a participatory way, through workshops. In addition, infrastructure and consumption points of the community were visited to study their needs, 
determine their emplacement and identify the electrical equipment to be used. With this information, the responsible technicians calculated a total energy demand of 4,441 Wh/day was estimated for houses and public institutions.

With regards to the available energy resources in the area, the wind was discarded due to the lack of wind in the region and the difficulty in implementing wind turbines. The information from a nearby weather station was used to evaluate solar radiation, matched with global radiation databases. In the case of the hydro-kinetic resource, the evaluation consists of an assessment of the speed taking into account variations in speed and flow that may occur across the year, as well as river ups and downs that could affect the bank or the depth where turbines are located.

\subsubsection{Design and implementation of the project}

First, a copy of the hydro-kinetic turbine model designed by Peter Garman (Figure 4), which had been successfully tested for six months in the community of El Paraíso in the Peruvian Amazon, was installed in the Coca river, 1 kilometer far from the community of San José del Coca. This turbine is characterized by overcoming the potential limitation for electricity generation in the Amazon, taking advantage of the kinetic energy of slow-moving and quiteflat rivers in the area. The design of the turbine blades assumes that the non-perpendicular incidence of the river into the swept area causes energy losses. The disadvantages of such a simple design, with partial use of hydro-kinetic energy and low river speed, are justified by the compromise between efficiency and simple construction.

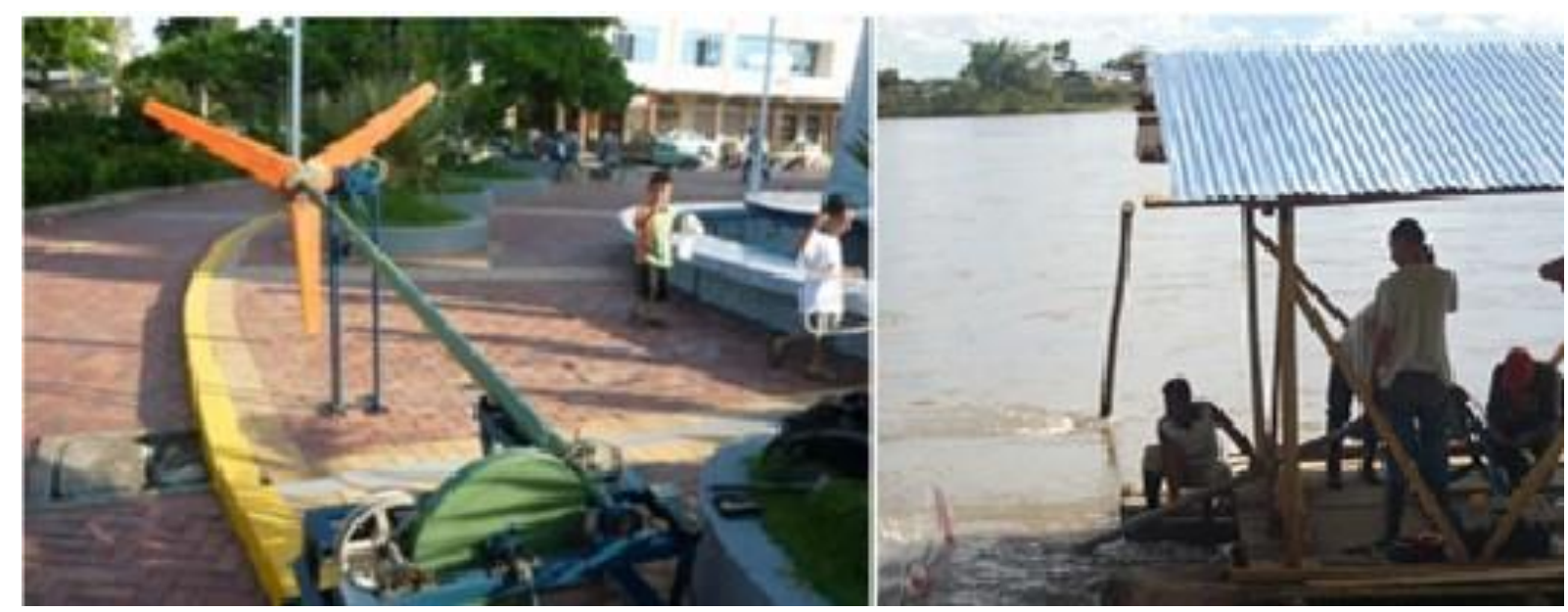

Figure 4. Hydro-kinetic turbine in San José del Coca, Ecuador [34]

The hydro-kinetic turbine has a gear ratio of 10, in order to increase the rotational speed of the generator which is then located in the support structure. The synchronous generator has a cylinder form, a diameter of around $40 \mathrm{~cm}$ and a weight of $42 \mathrm{~kg}$. There is a three-phase output, protected by a thermo-magnetic, which is transformed into DC current and stored in a battery bank. Working at a river speed of $1 \mathrm{~m} / \mathrm{s}$, the generator provides an AC current of $45 \mathrm{~V}$ between phases, with the blades rotating at $59 \mathrm{rpm}$ and the generator at $590 \mathrm{rpm}$. 
Subsequently, two additional turbines were installed at the same location, and electricity generation was complemented by six $100 \mathrm{Wp}$ PV panels. Initially, the microgrid was conceived to supply electricity only to the community spaces, but after the expansion in generation capacity, the network was extended to nearby houses. The microgrid operates in such a way that all generators provide DC power to a common bus that supplies batteries at $24 \mathrm{~V}$. The DC power is then transformed into AC through a three-phase inverter feeding a transformer that carries LV into MV, to transmit power until San José del Coca, one kilometer far from the Coca river. Once there, a second transformer switches into LV again, for distribution to end-users following a radial scheme.

\subsection{Alto Peru (Peru)}

The project of Alto Peru (province of San Pablo, Peru) is probably the most representative within the PAER program, given the combination of technologies used [37].The community consists of 58 houses, 1 school, 1 health center, 1 church, 2 restaurants and 2 shops. The project was developed with the goal of electrifying the entire community, using a pioneering approach in the country: using the most appropriate technology at each area, according to the location and demand of consumption points and the availability of energy resources. As a result, 5 different technologies were implemented, as shown in Table 2. The project was developed between 2009 and 2010 and benefited the population with access to electricity, while demonstrating the technical, economic and social feasibility of a combination of technologies in a community.

Table 2. Technologies used and beneficiaries in Alto Peru, Peru [37]

\begin{tabular}{cccc}
\hline Technology & Houses & $\begin{array}{c}\text { Beneficiaries } \\
\text { Institutions }\end{array}$ & Total \\
\hline Wind-PV microgrid & 7 & 1 (church) & $\mathbf{8}$ \\
Wind microgrid & 6 & 0 & $\mathbf{6}$ \\
Micro-hydro power plant & 4 & 1 (school) & $\mathbf{5}$ \\
PV microgrid & 2 & 1 (health center) & $\mathbf{5}$ \\
Individual PV systems & 39 & 2(restaurants) & $\mathbf{4 1}$ \\
Total & $\mathbf{5 8}$ & 2(shops) & $\mathbf{6 5}$ \\
\hline
\end{tabular}

\subsubsection{Preliminary evaluation of the project}

The data gathering and evaluation of the community were carried out to collect the information needed for the subsequent project design:

- Socioeconomic study. The location and demand of the consumption points to be electrified were analyzed. In order to examine the demand, the energy consumption prior to electrification was analyzed (candles, kerosene, batteries, etc.), as well as possible increases with the introduction of electricity and consumption in nearby communities. Thus, the following values were determined:

○ Houses, shops, restaurants and church: $280 \mathrm{Wh} /$ day (energy); $200 \mathrm{~W}$ (power); 2 days (autonomy). 
○ Health center: $975 \mathrm{Wh} /$ day (energy); $600 \mathrm{~W}$ (power); 2 days (autonomy).

○ School: $975 \mathrm{Wh} /$ day (energy); $1000 \mathrm{~W}$ (power); 2 days (autonomy).

The community organization was also studied, identifying the key stakeholders to ensure the success of the project, such as community leaders.

- Energy study. The renewable energy resources in the region were studied:

o Wind resource. Two anemometers were installed (near the school and the church) to measure the wind over a year. As a conservative assumption, the lowest resource month was chosen for the design. With the wind data, power curves of turbines and the topographic map, the wind was extrapolated at all the points (Figure 5).

- Solar resource. Unlike the wind resource, the solar resource was considered uniform throughout the community and determined from meteorological databases.

○ Hydro resource. A single waterfall was identified, shown as point HG in Figure 5.

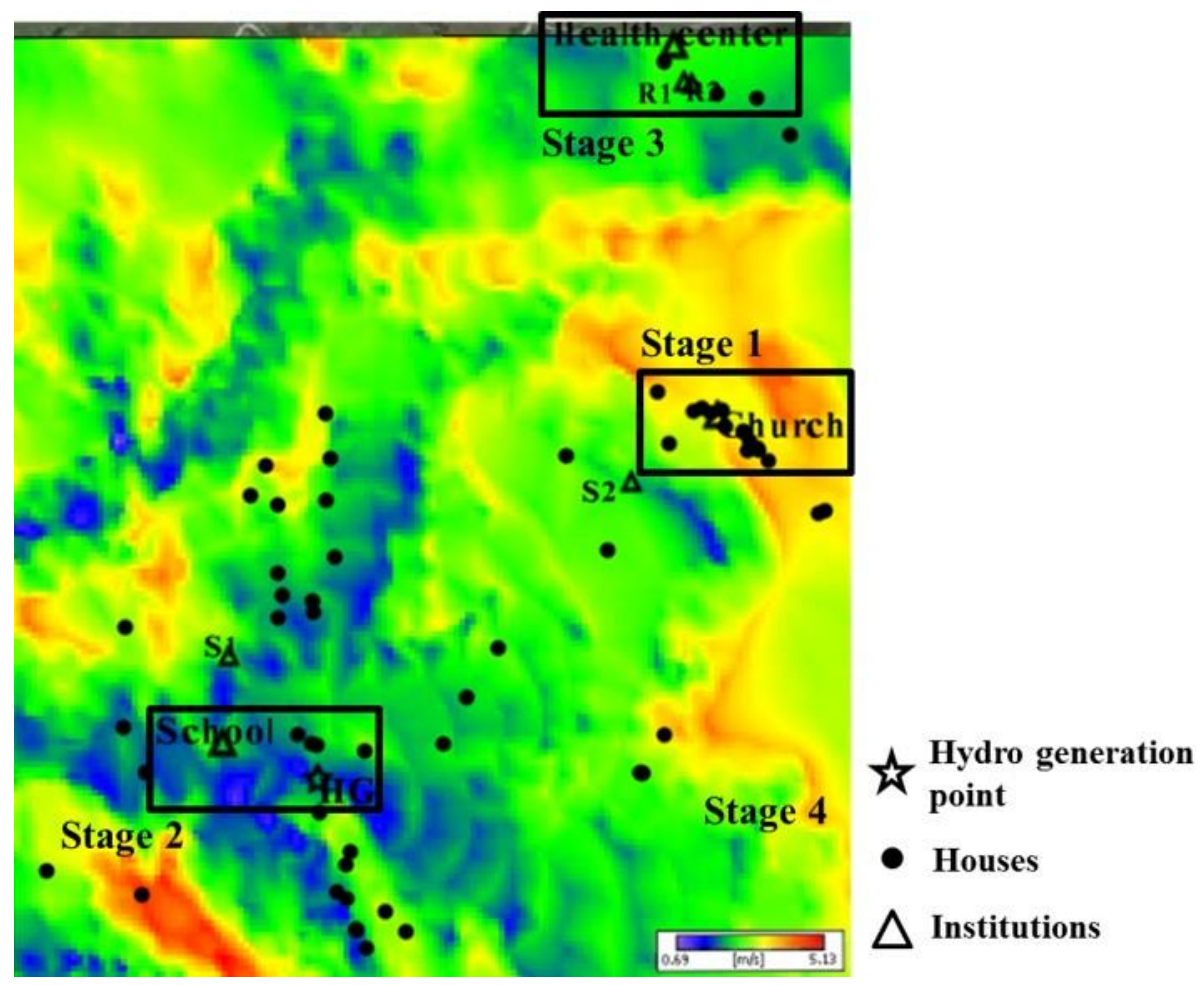

Figure 5. Location in the wind map of consumption points in Alto Peru, Peru [37]

\subsubsection{Design and implementation of the project}

Unlike the projects described previously, in the case of Alto Peru, the implementation was performed in four different stages that are described next.

\section{Stage 1. Wind-PV and wind microgrids}

First, a microgrid wind system was implemented in the area with the highest wind potential, located at the easternmost part of the community, as observed in Figure 5. More specifically, 14 consumption points (13 houses and the church) placed near to the access road were determined. To design the electrification system for these points, a two-step analysis was 
realized: first generating different electrification options by including different considerations and then selecting the most appropriate option through a discussion between experts and endusers. To generate each option, the technical and social experts involved in the project as well as the own population were interviewed about the features that could have an influence on the project appropriateness: (1) the electrical needs of population, studying different energy and power demand scenarios; (2) the land availability to install the equipment, studying a limit in the number of wind turbines that can be installed close to each other; (3) the equipment availability, considering the possibility of only using national (but small) wind turbines or importing bigger ones from abroad; and (4) the use of microgrids or individual systems. Combining the proposed scenarios, different solutions were generated using the mathematical model developed by Ferrer-Martí et al. [38]; which minimizes the cost while considering the detail of energy and power demands as well as technical constraints related to the equipment used. As a result, the location and size of all the equipment to be installed is obtained.

To complete the design, results were presented to the technical and social experts and to the community. Thus, they could compare the advantages and limitations of each option, considering the relative cost and characteristics. After discussing results, two microgrids were decided to supply, on the one hand, 7 houses and the church and, on the other hand, 6 houses, since they were cheaper than individual systems and they could promote community organization. Both microgrids are supplied by two $1200 \mathrm{~W}$ wind turbines manufactured in Peru, thus avoiding dependencies on abroad technologies. The system was completed by a battery backup with 2 days of autonomy and inverters with an equivalent power of 1600 and $1200 \mathrm{~W}$, respectively. Additionally, after a short period since the project implementation, two $95 \mathrm{Wp}$ PV panels were added to the big microgrid to compensate the relative limitations in end-users consumption in front of those of the smaller microgrid. This system represented the first microgrid small-scale wind project in Peru.

\section{Stage 2. Micro-hydro power plant}

Subsequently, a usable waterfall was identified close to the school, which is an institution considered a priority by the community. Given the river flow, the waterfall height and energy loss in the system, a $2 \mathrm{~kW}$ micro-hydro power plant was determined. The power capacity was conceived to supply the school $(1 \mathrm{~kW})$ and, additionally, the closest four houses $(0.8 \mathrm{~kW})$, assuming a safety margin. Due to its maintenance simplicity and low costs a Michell-Banki turbine was chosen. It must be noted that an operation schedule was defined, in order to combine the use of the river for electricity generation and irrigation purposes, avoiding harming agricultural activities.

\section{Stage 3. PV-microgrid}

After the micro-hydro power plant, another key point of the community was focused (the health center), for which the PV technology was decided. A microgrid could offer flexibility, giving the opportunity to occasionally increase the energy supply in the cases of, for example, medical emergencies. In this sense, the closeness of the 2 restaurants and 2 houses was 
utilized to implement a PV microgrid. More specifically, 8PV panels of $95 \mathrm{Wp}$ were installed together with a battery backup with 2 days of autonomy and a $1.5 \mathrm{~kW}$ inverter.

\section{Stage 4. Individual PV systems}

For the remaining points, a similar study than in Stage 1 was conducted. First, a set of electrification options analyzing different technical variations, determined from interviews with technical and social experts as well as the community itself, was generated. In particular, the following options were examined: (1) the technology to be used between wind, PV or a combination of both; (2) the covered energy uses, studying different demand scenarios; (3) the use of meters at all points, to establish an electricity tariff according to consumption, or only at microgrids, to reduce costs and establish a single electricity tariff; (4) the use of microgrids or individual systems; and (5) the inclusion of a minimum number of generation equipment, to ensure that if one fails, the remaining still provide part of the electricity. With this information, the electrification options arising from the combination of all scenarios were generated, using the mathematical model developed by Ferrer-Martí et al. [39].

Once generated all the options and given the amount of scenarios, a multi-criteria selection process was developed, organized into three parts. First, the selection criteria were defined, representing the point of view and interest of stakeholders involved in the project. Second, the criteria were weighted according to their relative importance. Third, each option was evaluated according to each criterion. With the weights of criteria and the option-criteria evaluation, a quality index was calculated for each electrification option; then presenting topranked options to the experts in charge of the project and the population, for the final selection. Finally, an individual PV system installed at each point was decided, consisting of $95 \mathrm{Wp}$ PV panel, a battery backup with 2 days of autonomy and a $300 \mathrm{~W}$ inverter.

\section{Project evaluation and comparison}

In Latin America, as in Asia and Africa, regional and national governments are making significant efforts to achieve full rural electrification, employing autonomous technologies as an effective alternative where the grid extension has limitations. In the previous section, 5 off-grid projects with different design processes and generation-distribution options have been presented. In this section, a comparison concerning the design process and the technologies implemented is carried out (Section 3.1). Then, the technical design is evaluated through specialized software (HOMER) and projects' real behavior is analyzed (Section 3.2).

\subsection{Project comparison}

Concerning the generation technologies, projects can be grouped between those that consider a single option, hybrid systems or a combination of technologies. Both in Saqa'saqa (Bolivia) and El Regalado (Peru) only one technology is used, which must be as continuous as possible to ensure the project success. In the first case, the existing river in the surroundings of the community can dry in some periods of the year, so the solar PV technology is decided. In the 
second case, the micro-hydro power plant ensures a sufficient generation across the entire year, assuming some security factors. In Jacuque (Venezuela) and San José del Coca (Ecuador) hybrid options are implemented, wind-PV and river turbine-PV respectively, which offer a great reliability in supply. In case of failure (due to the lack of resources or equipment breakdowns) the other technology still provides part of the electricity. Finally, Alto Peru (Peru) is a very large community, so using the same technology (single or hybrid) for all the points would result in a failure. For that reason, a combination of technologies, according to the location of the consumption points and a detailed analysis of energy resources, was chosen at each zone.

The studied projects can be also distinguished by the storage option utilized. In El Regalado (Peru), storage is not necessary since the power supply is continuous. In contrast, in Saqa'Saqa (Bolivia), San José del Coca (Ecuador) and Alto Peru (Peru), the energy resources are variable, and a time difference exists between generation and consumption. Consequently, a battery backup is necessary, with an autonomy between 2 and 3 days, depending on resources variability. Finally, in Jacuque (Venezuela) the battery backup is combined with a diesel generator, favored by the subsidized fuel costs in the country, minimizing the impact of fuel dependencies from abroad.

Regarding the electrical distribution, when the consumption points are close from each other, microgrids are preferable in front of individual systems, saving costs and extending the benefits of such configurations (higher flexibility and equity in consumption); what happens in Saqa'Saqa (Bolivia). In El Regalado (Peru) and San José del Coca (Ecuador), there is a significant distance between generation and consumption, so such a distance is covered using MV wires to minimize voltage drops, while LV wires are then used to distribute the electricity among end-users. In contrast, in Jacuque (Venezuela) and Alto Peru (Peru), a balance between the extension of microgrids and voltage drops is studied. In the first case, a single microgrid is combined with a set of individual systems. In the latter case, several microgrids and individual systems are deployed, which can be an interesting option for future projects in order to take advantage of microgrids at strategic points (schools, health centers, etc.) while using independent supplies for more scattered points. In this regard, individual points tend to have more limitations in consumption than microgrid ones, so compensation schemes can be conceived.

Finally, concerning technology, cost savings can be achieved through technologies simplification and adaptation to local conditions. This is the case of the hydro-kinetic turbines installed in Ecuador from previous experiences in Peru. It has also been achieved through standardization in Venezuela where, in addition, a state-owned manufacture produces wind turbines and PV panels. In Alto Peru (Peru) a discussion arose about the use of national or abroad wind turbines. The first option was decided to avoid foreign dependencies and promote the Peruvian market, though this process needs from governments support to strengthen technological developments. In general terms, the cost reduction in the PV technology makes it increasingly competitive, while the hydro energy (waterfalls or hydrokinetic turbines) has significant advantages in terms of generation capacity and supply 
quality. However, its usage is conditioned by the presence of nearby rivers. Small-scale wind turbines are less used and are not usually utilized as the single energy source, although this behavior is changing and their use is growing especially in hybrid schemes (wind-PVbattery). In windy areas, this technology can be cost effective and reliable.

\subsection{Project evaluation}

In this section, the 5 projects studied in this paper are analyzed through HOMER. HOMER is a software tool for optimal planning of hybrid rural electrification projects and allows modeling grid-connected and off-grid systems [40]. In a recent review, Bahramara et al. [41] highlight that HOMER is the most used software by researchers in the area of rural electrification to determine the optimum size of microgrid equipment, to plan the development of projects or to evaluate system behavior comparisons. In particular, HOMER enables project evaluation to identify whether they can satisfy the potential electricity demand in a reliable and sustainable way [42]. For instance, Azimoh et al. [43], made a technical analysis of hybrid microgrids based on HOMER model simulations.

In order to obtain the parameters to be used for the technical evaluation, the performance of the 5 projects is simulated for one year using HOMER Pro V. 3.5.9. In these simulations, the specific technical characteristics of generation equipment are considered as well as the real energy resources available at each project location. Thus, the design and technologies chosen are evaluated and projects' performance is obtained and compared with the design conceived. Moreover, projects were visited and promoters and operators were consulted, in order to analyze the real behavior of the electrification systems.

To evaluate the technical performance in terms of energy production and use of local energy resources, the factors proposed by the IEEE within the Electric Generating Unit Reliability, Availability and Productivity Standard [44] are used. Table 3 shows the results obtained with HOMER: Capacity Factor (\%), ratio between the current energy production and potentially generated energy at full capacity; Service Factor (\%), yearly percentage of time generating; and Energy Production, yearly energy production.

To validate the design, the capacity factor is focused. Results show that wind technologies have capacity factors around 15-20\%. In small wind systems, usual capacity factors range from $15 \%$ to $20 \%$, so the use of wind technologies in these projects is appropriate [45]. In terms of solar energy, capacity factors are always over $14 \%$, which is a suitable value [46]. On their behalf, hydraulic projects have the higher capacity factors, up to $85 \%$.

Concerning the analysis of projects' real behavior, first, the energy production and demand are compared. Although 6-13\% of the energy may be lost in conversion [47] and distribution [48], results show that, for all the projects and technologies, yearly energy generation is greater than demand so end-user requirements are fulfilled. Demand fulfillment was indeed verified during project visits and by promoters and operators. 
Table 3. Evaluation parameters obtained from HOMER

\begin{tabular}{|c|c|c|c|c|c|c|}
\hline Project & Technologies & $\begin{array}{c}\text { Resource } \\
\text { (installed capacity, } \mathrm{kW} \text { ) }\end{array}$ & $\begin{array}{c}\text { Capacity } \\
\text { Factor }(\%)\end{array}$ & $\begin{array}{c}\text { Service } \\
\text { Factor }(\%)\end{array}$ & $\begin{array}{c}\text { Demand } \\
(\mathrm{kWh} / \text { year })\end{array}$ & $\begin{array}{c}\text { Energy } \\
\text { Production } \\
\text { (kWh/year) }\end{array}$ \\
\hline Saqa'Saqa & PV microgrid & Solar (0.72) & $21.2 \%$ & $49.7 \%$ & 1,168 & 1,337 \\
\hline El Regalado & $\begin{array}{c}\text { Hydro } \\
\text { microgrid }\end{array}$ & Hydro (12) & $85.0 \%$ & $100.0 \%$ & 9,375 & 89,355 \\
\hline \multirow{3}{*}{ Jacuque } & \multirow{2}{*}{$\begin{array}{l}\text { Wind-PV } \\
\text { microgrid }\end{array}$} & Solar (3) & $21.6 \%$ & $49.5 \%$ & \multirow{2}{*}{7,300} & \multirow{2}{*}{9,761} \\
\hline & & Wind (3) & $15.6 \%$ & $94.8 \%$ & & \\
\hline & $\begin{array}{c}\text { Individual } \\
\text { PV systems }\end{array}$ & Solar (0.6) & $21.6 \%$ & $49.8 \%$ & 730 & 1,135 \\
\hline \multirow{2}{*}{$\begin{array}{l}\text { San José del } \\
\text { Coca }\end{array}$} & \multirow{2}{*}{$\begin{array}{l}\text { Hydro-kinetic } \\
\text { PV microgrid }\end{array}$} & Solar (0.6) & $13.6 \%$ & $50.0 \%$ & \multirow{2}{*}{1,621} & \multirow{2}{*}{6,624} \\
\hline & & Hydro-Kinetic (0.9) & $33.5 \%$ & $100.0 \%$ & & \\
\hline \multirow{6}{*}{ Alto Peru } & $\begin{array}{c}\text { Hydro } \\
\text { microgrid }\end{array}$ & Hydro (2) & $42.5 \%$ & $50.0 \%$ & 765 & 7,533 \\
\hline & PV microgrid & Solar (0.76) & $14.9 \%$ & $50.3 \%$ & 765 & 992 \\
\hline & $\begin{array}{l}\text { Wind } \\
\text { microgrid }\end{array}$ & Wind (2.4) & $19.9 \%$ & $89.3 \%$ & 613 & 4,187 \\
\hline & \multirow{2}{*}{$\begin{array}{l}\text { Wind-PV } \\
\text { microgrid }\end{array}$} & Wind (2.4) & $19.9 \%$ & $89.3 \%$ & \multirow{2}{*}{818} & \multirow{2}{*}{4,435} \\
\hline & & Solar (0.19) & $14.9 \%$ & $50.3 \%$ & & \\
\hline & $\begin{array}{c}\text { Individual } \\
\text { PV systems }\end{array}$ & Solar (0.95) & $14.9 \%$ & $50.3 \%$ & 102 & 124 \\
\hline
\end{tabular}

Results also show that projects using hydraulic technologies have the greatest generation capacity since the technical design is based on the power demand, and a significant amount of energy may be produced at non-demand periods. Moreover, thanks to the lower unit cost of such technology in comparison with other options such as wind and solar [49], hydro projects tend to oversize the energy generation to allow user and demand increases. In particular, in El Regalado, the low hydro unit cost and the resource availability allow a project design that considers a significant increase in population. For solar and wind technologies, the energy excess is mainly caused by resources seasonality: the energy generation in high resource periods may be much higher than in low resource periods used as baseline for projects design. In a minor significance, scalability of technology and equipment available may cause power generation oversizing too.

In sum, the projects have an energy excess that enables new electricity usages to promote socioeconomic development of communities. However, there are significant differences on the energy excess for the different technologies implemented in a same project. This means that users of the same community may have a different electricity supply. For instance, in Alto Peru, although the estimated demand is always fulfilled, some inequities in supply are causing some conflicts between families.

In terms of service factor, results show that the hydro and wind technologies work much more hours per year than the solar technology. More working hours may cause more technical problems and more maintenance operations. In fact, in the wind-PV microgrids of Jacuque and Alto Peru, the wind turbines have much more technical problems than the PV panels. In these projects, hybrid technology combinations show to be appropriate: although 
the wind technology may produce more energy in windy periods, the solar technology is useful to ensure and guarantee a basic energy production.

\section{Conclusions}

The Andean countries have many similarities in terms of the abundance of renewable energy resources largely distributed across their territories. This condition allows rural electrification using renewable technologies to be feasible in remote areas far from national grids. In this paper, five isolated microgrid rural electrification projects have been reviewed, using different options for the electrical generation and distribution, as well as different methods for data gathering and systems design. The technologies used are: a PV microgrid in Saqa'saqa (Bolivia), a micro-hydro power plant in El Regalado (Peru); a hydro-kinetic-PV microgrid in San José del Coca (Ecuador); a wind-PV-diesel microgrid and individual PV systems in Jacuque (Venezuela); and a combination of five different technologies in Alto Peru (Peru): a wind-PV, a wind and a PV microgrids, a micro-hydro power plant and individual PV systems.

When comparing projects, it can be observed that the demand estimation can be done through surveys, according to the socioeconomic characteristics of population and by forward-looking statements. As generation technologies, some projects are based on a single option, others use hybrid systems, improving reliability of supply, and others combine various technologies, depending on the location of the consumption points and energy resources. Storage systems are determined by the availability of resources and the balance between the estimated demand and generation capacity. A battery backup and, in some cases, an additional diesel generator are commonly used. Finally, distribution microgrids use medium voltage for long distances and low voltage between nearby points. Moreover, in some projects the balance between microgrids extension and individual supplies is studied to minimize costs and voltage drops. For each project, the technical design has been evaluated and its real behavior has been analyzed through a one-year simulation based on HOMER software. Moreover, projects were visited and promoters and operators consulted. Results show that all the technologies are appropriate and energy production always fulfills demand requirements. In fact, there is an energy excess, mainly due to resources seasonality, that enables new electricity usages to promote socioeconomic development of communities. However, differences in the energy supply may cause conflicts which are important to tackle. Finally, results also confirm the advantages of hybrid wind-PV systems that may produce more energy with a guaranteed basic supply.

This revision of rural electrification projects with renewable energy in Andean countries can be used as an example for future projects or electrification programs in the region. Moreover, such experiences may be extended to other Latin American regions as well as areas in Africa and Asia with similar natural and socioeconomic conditions. 


\section{Acknowledgment}

This project was funded by the Spanish Ministry of Science and Innovation (project ENE 2015-67253), the UCD Energy21 program, co-financed through the Marie Curie FP7-PEOPLE-2013-COFUND program, and the Center for Cooperation Development (CCD) of the Universitat Politècnica de Catalunya (UPC). The authors are very grateful for all the support received from the developers of the projects described.

\section{References}

[1] IEA. World Energy Outlook 2015. Paris: 2015.

[2] IEA. Energy for All: Financing access for the poor. World Energy Outlook 2011:52.

[3] Iddrisu I, Bhattacharyya SC. Sustainable energy development index: a multi-dimensional indicator for measuring sustainable energy development. Renew Sustain Energy Rev 2015;50:513-30. doi:10.1016/j.rser.2015.05.032.

[4] Akorede MF, Hizam H, Pouresmaeil E. Distributed energy resources and benefits to the environment. Renew Sustain Energy Rev 2010;14:724-34. doi:10.1016/j.rser.2009.10.025.

[5] Kenfack J, Neirac FP, Tatietse TT, Mayer D, Fogue M, Lejeune A. Microhydro-PV-hybrid system: sizing a small hydro-PV-hybrid system for rural electrification in developing countries. Renew Energy 2009;34:2259-63. doi:10.1016/j.renene.2008.12.038.

[6] Mendes G, Ioakimidis C, Ferrão P. On the planning and analysis of integrated community energy systems: a review and survey of available tools. Renew Sustain Energy Rev 2011;15:4836-54. doi:10.1016/j.rser.2011.07.067.

[7] Yadoo A, Cruickshank H. The role for low carbon electrification technologies in poverty reduction and climate change strategies: a focus on renewable energy mini-grids with case studies in Nepal, Peru and Kenya. Energy Policy 2012;42:591-602. doi:10.1016/j.enpol.2011.12.029.

[8] Blyden BK. Modified microgrid concept for rural electrification in Africa. 2006 IEEE Power Eng Soc Gen Meet 2006:5 pp. doi:10.1109/PES.2006.1709540.

[9] Zahedi A. Solar photovoltaic (PV) energy; latest developments in the building integrated and hybrid PV systems. Renew Energy 2006;31:711-8. doi:10.1016/j.renene.2005.08.007.

[10] Lew DJ. Alternatives to coal and candles: wind power in China. Energy Policy 2000;28:271-86. doi:10.1016/S0301-4215(99)00077-4.

[11] Orrell A, Rhoads-Weaver H. 2013 distributed wind market report 2014.

[12] Sørnes K. Small-scale water current turbines for river applications. ZERO - Zero Emission Resource Organisation 2010.

[13] Camblong H, Sarr J, Niang AT, Curea O, Alzola JA, Sylla EH, et al. Micro-grids project, part 1: analysis of rural electrification with high content of renewable energy sources in Senegal. Renew Energy 2009;34:2141-50. doi:10.1016/j.renene.2009.01.015.

[14] Deshmukh MK, Deshmukh SS. Modeling of hybrid renewable energy systems. Renew Sustain Energy Rev 2008;12:235-49. doi:10.1016/j.rser.2006.07.011.

[15] NREL. Renewable energy in China - Renewable energy business partnerships in China 2004:2.

[16] Shyu CW. Rural electrification program with renewable energy sources: an analysis of China's Township Electrification Program. Energy Policy 2012;51:842-53. doi:10.1016/j.enpol.2012.09.036.

[17] Schnitzer D. Microgrids for Rural Electrification: a critical review of best practices based on seven case studies. Berkeley: United Nations Foundation; 2014.

[18] MNRE. Strategic plan for new and renewable energy sector government of India. Renew Energy 2011:1-85.

[19] Thirumurthy N, Harrington L, Martin D, Thomas L, Thirumurthy N, Harrington L. Opportunities and challenges for solar minigrid development in rural. NREL Technical Report 2012.

[20] SE4All-GFT. Sustainable Energy for All. Annual Report. IRENA 2014:57. doi:10.4135/9781412963855.n1148.

[21] ADB. SE4ALL Africa Hub. Annual Report 2014-2015. African Development Bank Group 2015:1. doi:10.1017/CBO9781107415324.004.

[22] Wiemann M, Ng L, Lecoque D. Best practices for clean energy access in Africa 2015:1-30.

[23] Gómez MF, Silveira S. Rural electrification of the Brazilian Amazon - achievements and lessons. Energy Policy 2010;38:6251-60. doi:10.1016/j.enpol.2010.06.013.

[24] Sánchez AS, Torres EA, Kalid RA. Renewable energy generation for the rural electrification of isolated 
communities in the Amazon Region. Renew Sustain Energy Rev 2015;49:278-90. doi:10.1016/j.rser.2015.04.075.

[25] Mitra I. A renewable island life. Electricity from renewables on small islands. Refocus 2006;7:38-41. doi:10.1016/S1471-0846(06)70658-8.

[26] Cubaenergía. Energías renovables, experiencia de la Isla de la Juventud. Clips de Energía 2014;17:1-2.

[27] Fontaine G. The effects of governance modes on the energy matrix of Andean countries. Energy Policy 2011;39:2888-98. doi:10.1016/j.enpol.2011.02.064.

[28] World Bank. Access to electricity (\% of population). Sustainable Energy for All (SE4ALL). Database from World Bank 2015.

[29] World Bank. Population, total. United Nations Population Division. World Population Prospect 2015.

[30] IEA. World Energy Outlook 2012.

[31] Ferrer-Martí L, Cubells A, Velo E, Carrillo M. Proyectos de electrificación rural con energías renovables. Icaria (Ed,), Tecnología y Desarrollo Humano 2013:288.

[32] MEM. Plan estratégico sectorial multinanual modificado 2008-2011. Lima: Ministerio de Energía y Minas: 2008.

[33] Lillo P, Ferrer-Martí L, Boni A, Fernández-Baldor Á. Assessing management models for off-grid renewable energy electrification projects using the Human Development approach: case study in Peru. Energy Sustain Dev 2015;25:17-26. doi:10.1016/j.esd.2014.11.003.

[34] Practical Action. Diagnóstico socioeconómico - Comunidad El Regalado. Cajamarca: 2008.

[35] OLADE. Índices latinoamericanos de electrificación. Organización Latinoamericana de Energía 2014.

[36] Fundelec. Sembrando Luz: promoviendo las energías renovables en zonas aisladas, indígenas y fronterizas del país 2012:32.

[37] Domenech B, Ferrer-Martí L, Lillo P, Pastor R, Chiroque J. A community electrification project: combination of microgrids and household systems fed by wind, PV or micro-hydro energies according to micro-scale resource evaluation and social constraints. Energy Sustain Dev 2014;23:275-85. doi:10.1016/j.esd.2014.09.007.

[38] Ferrer-Martí L, Pastor R, Capó GM VE. Optimizing microwind rural electrification projects. A case study in Peru. J Glob Optim 2011;50:127-43.

[39] Ferrer-Martí L, Domenech B, García-Villoria A, Pastor R. A MILP model to design hybrid windphotovoltaic isolated rural electrification projects in developing countries. Eur J Oper Res 2013;226:293-300. doi:10.1016/j.ejor.2012.11.018.

[40] Ohiare S. Expanding electricity access to all in Nigeria: a spatial planning and cost analysis. Energy Sustain Soc 2015;5:1-18. doi:10.1186/s13705-015-0037-9.

[41] Bahramara S, Moghaddam MP, Haghifam MR. Optimal planning of hybrid renewable energy systems using HOMER: a review. Renew Sustain Energy Rev 2016;62:609-20. doi:10.1016/j.rser.2016.05.039.

[42] Bhattacharyya S. Rural electrification through decentralised off-grid systems in developing countries. Green Energy Technol 2013;116:13-39. doi:10.1007/978-1-4471-4673-5.

[43] Azimoh CL, Klintenberg P, Wallin F, Karlsson B, Mbohwa C. Electricity for development: mini-grid solution for rural electrification in South Africa. Energy Convers Manag 2016;110:268-77. doi:10.1016/j.enconman.2015.12.015.

[44] IEEE Power Engineering Society. Standard definitions for use in reporting electric generating unit reliability, availability, and productivity. Vol. 2006-2007. doi:10.1109/IEEESTD.2007.335902.

[45] Tummala A, Velamati RK, Sinha DK, Indraja V, Krishna VH. A review on small scale wind turbines. Renew Sustain Energy Rev 2016;56:1351-71. doi:10.1016/j.rser.2015.12.027.

[46] EIA. Electric power monthly with data for November 2016. Energy Information Agency; Washington: 2017.

[47] He F, Ji L, Zgonena T, Flueckiger C, Jaeckel B, Brazis P. PV and inverter coupling induced system efficiency loss. 2014 IEEE 40th Photovolt. Spec. Conf. PVSC 2014:1938-43. doi:10.1109/PVSC.2014.6925305.

[48] Minchala-Avila LI, Garza-Castanon L, Zhang Y, Ferrer HJA. Optimal energy management for stable operation of an islanded microgrid. IEEE Trans Ind Informatics 2016;12:1361-70. doi:10.1109/TII.2016.2569525.

[49] Varun, Prakash R, Bhat IK. Energy, economics and environmental impacts of renewable energy systems. Renew Sustain Energy Rev 2009;13:2716-21. doi:10.1016/j.rser.2009.05.007. 